\title{
Limitations of fibre optic distributed temperature sensing for quantifying surface water groundwater interactions
}

\author{
H. Roshan ${ }^{1}$, M. Young ${ }^{1}$, M. S. Andersen ${ }^{1,2}$, and R. I. Acworth ${ }^{1,2}$ \\ ${ }^{1}$ Connected Waters Initiative Research Centre, University of New South Wales, 110 King St, \\ Manly Vale, NSW 2093, Australia \\ ${ }^{2}$ National Centre for Groundwater Research and Training, Sydney, Australia \\ Received: 10 June 2014 - Accepted: 9 July 2014 - Published: 18 July 2014 \\ Correspondence to: H. Roshan (h.roshan@unsw.edu.au) \\ Published by Copernicus Publications on behalf of the European Geosciences Union.
}

\begin{abstract}
Studies of surface water-groundwater interactions using fiber optic distributed temperature sensing (FO-DTS) has increased in recent years. However, only a few studies to date have explored the limitations of FO-DTS in detecting groundwater discharge to 5 streams. A FO_DTS system was therefore tested in a flume under controlled laboratory conditions for its ability to accurately measure the discharge of hot or cold groundwater into a simulated surface water flow. In the experiment the surface water (SW) and groundwater (GW) velocities, expressed as ratios $\left(v_{\mathrm{gw}} / v_{\mathrm{sw}}\right)$, were varied from $0.21 \%$ to $61.7 \%$; temperature difference between SW-GW were varied from 2 to $10^{\circ} \mathrm{C}$; the 10 direction of temperature gradient were varied with both cold and-hot water injection; and two different bed materials were used to investigate their effects on FO_DTS's detection limit of groundwater discharge. The ability of the FO_DTS system to detect the discharge of groundwater of a different temperature in the laboratory environment was found to be mainly dependent upon the surface and groundwater flow velocities and 15 their temperature difference. A correlation was proposed to estimate the groundwater discharge from temperature. The correlation is valid when the ratio of the apparent temperature response to the source temperature difference is above 0.02 .
\end{abstract}

\section{Introduction}

The accurate quantification of fluxes and directions of water flows between different 20 natural reservoirs (i.e. aquifers, stream and lakes) is critical to those who utilise it as a fresh water resource (drinking water, irrigation and livestock production) and those who use it for industrial purposes as well as its use for environmental and recreational purposes (Blakey, 1966). The use of heat to estimate water flows is one of the main tools to quantify surface water-groundwater interactions. The heat method extends back to Suzuki (1960) who derived an analytical solution for the one-dimensional transient heat-flow equation to determine the infiltration of water from rice paddies. Since 
then, heat as a tracer has been developed by numerous researchers and was largely based upon discrete points of measurement along the streambed. Temperature measurements became more precise and the amount of data collected increased as technology progressed. The latest improvement in technology has been the development

5 in the use of fiber optics (Selker et al., 2006a), which can be deployed as a continuous measurement along the streambed with reported spatial and thermal resolutions of $1 \mathrm{~m}$ and $0.01^{\circ} \mathrm{C}$, respectively (Selker et al., 2006a, b).

The use of fiber optics to measure temperature was originally developed for pipeline monitoring, fire detection and temperature monitoring in oil wellbores. Subsequently,

10 its potential use in the field of hydrology was discovered (Kersey, 2000). Since then the method has been applied to a number of field settings (Selker et al., 2006a, b). As an emerging technology in the field of hydrology, researchers have been trying to assess DTS capabilities and limitations in particular, its measured temperature accuracy and the limitation in detection of groundwater discharge to streams. For instance, the ef-

15 fect of direct solar radiation on the fibre optic cables and its effect on the temperature reading has been investigated by Neilson et al. (2010) and shown to cause significant differences from independently measured temperatures. A laboratory experiment was carried out by Rose et al. (2013) to investigate the accuracy of a DTS system in detecting the size and location of a temperature anomaly resulted from a heat source.

20 Their results show that the accuracy of FO-DTS in detecting temperature anomalies decreased as the size of the temperature contrast was reduced.

Importantly, the temporal and spatial precision of the FO-DTS temperature measurements are critical factors for dynamic conditions. For instance, Tyler et al. (2009) showed that the temporal precision (repeatability) of three different DTS instruments 25 have $0.08,0.13$ and $0.31^{\circ} \mathrm{C}$ standard deviation for $1 \mathrm{~min}$ measurement, respectively, while the spatial precision is better for the same instruments having the standard deviation of $0.02,0.04$ and $0.08^{\circ} \mathrm{C}$, respectively.

In addition, the attempts have been made to quantify the detection limit of flow estimation from DTS temperature measurement including the work of Briggs et al. (2012)

8169

who used FO-DTS in a natural stream-groundwater system having a ratio of groundwater to surface water flow rates of about $5 \%$. They assessed that the quality of results obtained with DTS were comparable to those obtained with geochemical tracers. For another stream-groundwater system (a natural first-order stream), Lauer et al. (2013) 5 investigated the limit of flow estimation from temperature data of DTS. They tested their system for ratios of groundwater to surface water flow of $<1$ to $19 \%$ and concluded that ratios above $2 \%$ can be determined from the measured DTS temperature response using the energy balance equation. However, their work was carried out in a field environment where the controlling parameters such as groundwater and surface

10 water velocities, their temperature difference and etc. are naturally uncertain and cannot be precisely manipulated to cover a range of conditions. In addition, the effect of these controlling parameters on the obtained limit has not been thoroughly investigated yet. We have therefore tested the performance of a FO-DTS system in a well-controlled environment by injecting groundwater of constant temperature into a simulated gaining stream environment in a temperature controlled installation. By eliminating heat processes likely to occur in the field, such as direct solar radiation on the fiber optic cable and by avoiding the uncertainties caused by general field heterogeneity in flow paths and variable surface and groundwater flow rates, we seek to find the temperature detection limit and consequently the limit of detection for groundwater outflow of this 20 methodology. We have designed the experiment to investigate the effect of different parameters such as: the ratio of groundwater to surface water flow velocities; temperature difference between surface and groundwater sources; type of bed material; hot and cold groundwater outflow (and its density effect) on this limit.

\section{Experimental setup}

25 The pre-existing $7.11 \mathrm{~m}$ flume (Fig. 1a) was modified to include a groundwater inflow section. This was achieved by adding $15 \mathrm{~mm}$ thick Perspex sheeting to the bottom of the flume section. The centre $300 \mathrm{~mm} \times 300 \mathrm{~mm}$ of the Perspex was perforated with 
$3 \mathrm{~mm}$ holes at $7 \mathrm{~mm}$ spacing, resulting in a void ratio of 0.138 . At the base of the flume, a $300 \mathrm{~mm} \times 300 \mathrm{~mm} \times 40 \mathrm{~mm}$ volume was constructed where the injected groundwater could be introduced through a tube sitting inside half a PVC pipe glued to the side of the flume. This minimised heat transfer between the surface water and the groundwa-

5 ter feed tube. A fiber optic cable was installed within the flume to record the surface water temperatures affected by groundwater injected near the start of the flume. The spatial resolution of the fiber optic temperature measurements along the flume was increased by coiling the fiber optic cable around a PVC tube. After testing different diameter PVC tubing, it was found that $42 \mathrm{~mm}$ diameter tubing struck the best balance

10 between spatial resolution and proximity to the flume floor and the groundwater inflow. Approximately $750 \mathrm{~m}$ of fiber optic cable (OM3) was wrapped around the PVC tube and $50 \mathrm{~m}$ of spare fiber optic cable on both ends were used for calibration in an ice bath during the testing. The PVC tube was filled with gravel to make it sit on the flume floor and it was securely capped at both ends to prevent water ingress. A DTS system

15 (Oryx, Sensornet, UK) sent and received signals from the fiber optic cable in doubleended configuration. Temperature was also measured independently by Hobo loggers (Pro v2) in the injection section, the ice bath and inside the flume on the upstream side before the injection section. The temperature of the groundwater feed-tank was also recorded by a temperature logger (Fluke 1523/24) at all times. An insulated icebox

20 was used for maintaining the groundwater at a set temperature, which was kept constant and well mixed throughout the testing by a mixer. Figure $1 \mathrm{~b}$ shows an example of the temperature measurements along the cable with reduced temperatures at the groundwater injection section and in the calibration bath.

A Sontek Acoustic Doppler Velocimeter (ADV) was installed approximately $3 \mathrm{~m}$ down25 stream of the injection section to measure the surface water velocity. Surface water in the flume was fed by gravity from the nearby dam (Manly Dam, Sydney, NSW) and flow was regulated through a gate at the downstream side of the flume. A peristaltic pump was used to deliver and regulate the groundwater flows into the injection section. In initial tests, five different surface water velocities and five different groundwater

8171

velocities were used leading to 25 different velocity ratios varying from 0.21 to $61.7 \%$ (corresponding to flow ratios of 0.07 to $21.5 \%$ ) with a $10^{\circ} \mathrm{C}$ temperature difference between surface and groundwater. The velocities (and corresponding flow rates) used for surface water and groundwater in the experiment are summarised in Table S1 in the 5 Supplement. The reason for using velocity ratio instead of flow ratio is to allow generalisation of the results to other experiments or field settings. For instance, similar flow rate ratios can be obtained at different velocities by varying the surface area. Therefore, the flow ratio does not uniquely relate to the apparent temperature response (considering that the velocity is the main factor controlling the heat transfer in the system).

10 In sensitivity tests, the temperature difference between surface water and groundwater was varied from 2 to $10^{\circ} \mathrm{C}$ to investigate the effect of the source temperature difference on apparent temperature response for one of the investigated velocity ratios (0.024). In the second sensitivity test, both hot and cold groundwater was injected into the surface water in order to investigate the effect of change in water density on the apparent temperature response. The source temperature difference was set to +10 and $-10^{\circ} \mathrm{C}$ for the hot and cold water injection, respectively and four different velocity ratios (a: 0.024 , b: 0.002 , c: 0.55 and $\mathrm{d}: 0.617$ ) are tested to cover a wider range of surface water/groundwater velocities (Table S2 in the Supplement). In two experiments, dyes were also added to the groundwater to observe the uniformity of water flow through the injection section.

The third sensitivity test involves placing a $4 \mathrm{~cm}$ thick gravel layer on the bottom of the flume instead of just having a glass bottom, to form a porous bed to investigate its effect on the apparent temperature response (the source temperature difference was set to $\left.+10^{\circ} \mathrm{C}\right)$ where the surface water velocity $\left(0.1197 \mathrm{~m} \mathrm{~s}^{-1}\right)$ and the groundwater 25 velocity $\left(2.818 \times 10^{-3} \mathrm{~m} \mathrm{~s}^{-1}\right)$ were kept constant throughout this test.

In order to investigate the temperature precision of the DTS instrument, fibre optic temperature measurements in an ice bath were compared with a high precision/high resolution temperature logger and probe (1523/24 Reference Thermometer from FLUKE with thermal precision of $0.002^{\circ} \mathrm{C}$ ). 
DTS temperature traces for analysis were taken 20 min after the onset of groundwater injection in each test, when the temperature reached steady state. The raw output of stoke/anti-stoke backscatters provided by the DTS instrument was used to calcu-

5 late the temperature of the fiber optic cable using the algorithm proposed by van de Giesen et al. (2012). The cumulative differential attenuation of the cable showing sharp transitions in temperature (due to splice, bends, etc.) is presented in Fig. 2. A linear fit was applied to the data and the fit was used for attenuation correction. The temperature accuracy was assessed by comparing the DTS measurement in an ice bath

10 (for two sections of the cable with nearly $50 \mathrm{~m}$ length each) with the Fluke reference thermometer.

The RMSE, Bias and Standard deviation were calculated for all measurements (compared with the Fluke reference thermometer) in the first and second sections of the cable in the ice bath and the results are presented in Fig. 3. The RMSE of the first and

15 second sections of the cable fluctuate around $0.025{ }^{\circ} \mathrm{C}$ which is very similar to their standard deviations. The bias fluctuates around zero although a slight off-bias can be observed in both first and second part of cable in the ice bath. Therefore it can be concluded that an accuracy of at least $0.1^{\circ} \mathrm{C}$ can be attained in the tests.

The surface water background temperature was obtained by a logger at the up20 stream side of the flume. This temperature was compared with the minimum temperature measurement (or maximum in case of a hot groundwater injection) caused by the groundwater injection. So the apparent temperature response (ATR) was obtained as a difference by these two values for each individual test (Fig. 4). In contrast we define the known temperature difference between the two water sources as the source 25 temperature difference (STD).

\section{Results}

\subsection{Effect of the groundwater/surface water velocities on the apparent temperature response}

Figure 5 summarises the results by reporting the ratio of apparent temperature re5 sponse to source temperature difference (ATR/STD) vs. the velocity ratio of groundwater to surface water $\left(v_{\mathrm{gw}} / v_{\mathrm{sw}}\right)$ for all the tests (Table S1) on a semi-log scale. As seen from Fig. 5, the data scatter along a straight line on the semi-scale graph. It was observed that by increasing the surface water velocity or decreasing groundwater velocity the intensity of the apparent temperature response decreases. It is also seen that the 10 ATR/STD spreads across a wide range of $v_{\mathrm{gw}} / v_{\mathrm{sw}}$ when the ATR/STD is below 0.02 .

\subsection{Effects of varying the source temperature difference}

Figure 6 summarises the tests where the temperature difference, between surface water and the groundwater was varied in four steps $\left(2,4,6,8\right.$ and $\left.10^{\circ} \mathrm{C}\right)$ while the surface water velocity $\left(0.11965 \mathrm{~m} \mathrm{~s}^{-1}\right)$ and groundwater velocity $\left(2.818 \times 10^{-3} \mathrm{~m} \mathrm{~s}^{-1}\right)$ were kept 15 constant. From Fig. 6 , it can be seen that an increase in the source temperature difference is linearly related to the apparent temperature response.

\subsection{Effect of bedding material on apparent temperature response}

Although heat transfer is mostly assumed to be dominated by convection (by fluid motion) for FO-DTS applications (Westhoff et al., 2007), the heat conduction between the

20 fiber optic cable and the underlying bedding can also have an influence on the heat transfer. This hypothesis was put to the test by applying a layer of gravel on the bottom of the flume. The apparent temperature response both with and without a gravel bed beneath the cable are presented in Fig. 7. From this figure it can be observed that when the fiber optic cable lies on the gravel, the apparent temperature response

25 is higher than when it is in contact with the flume bottom (glass). So it seems that the 
flow regime is modified close to cable due to presence of gravel with tortuosity. This tortuosity causes the water to move quicker within the pores and flow out of the gravel faster toward the cable which in turn enhances the heat transfer by convection. In addition, the conduction may have contributed to temperature changes as the thermal 5 conductivity of gravel is lower than that of glass.

\subsection{Effect of hot/cold water injection on the apparent temperature response}

The apparent temperature response for both hot and cold water injections for four different velocity cases (Table S2) is presented in Fig. 8. This Figure illustrates that the difference in apparent temperature response between cold and hot water injections

10 are most prominent when both the surface water and groundwater velocities are low $\left(v_{\mathrm{gw}}=0.00475 \mathrm{~m} \mathrm{~s}^{-1}\right.$ and $\left.v_{\mathrm{sw}}=2.54 \times 10^{-4} \mathrm{~m} \mathrm{~s}^{-1}\right)$ and in fact it is not a function of the ratio. For the cases with higher groundwater and surface water velocities, both the cold and hot water injections have almost the same effect on the apparent temperature response.

\section{$15 \quad 4.5$ Groundwater-surface water mixing process}

In two experiments, dyes were also added to the groundwater to observe the uniformity of water flow through the injection section. The dye tests showed that in some cases the water is not fully mixed when it discharges from the injection section (especially when the groundwater velocity is high) and depending on the surface water and groundwater

20 velocities the mixing takes place on different spatial and temporal scales (Figs. S1 and $\mathrm{S} 2$ in the Supplement).

\subsection{Extending the results of the tests obtained at for $a 10^{\circ} \mathrm{C}$ source temperature difference to other temperatures}

In order to extend the result of the tests carried out with a $10^{\circ} \mathrm{C}$ source tempera25 ture difference (Fig. 5) to other source temperature differences (here to $2^{\circ} \mathrm{C}$ ), the data 8175

presented in Figs. 5 and 6 are re-called. Figure 5 was plotted based on the ratio of the apparent temperature response to the source temperature difference where the temperature difference is $10^{\circ} \mathrm{C}$. One can readily change the temperature difference from 10 to $2^{\circ} \mathrm{C}$ on Fig. 5 by knowing the relationship between the apparent tempera5 ture response and the source temperature difference. The relationship is a linear type and can be extracted from Fig. 6 when different source temperatures were tested. As discussed, the ATR/STD $=0.02$ was the threshold defined in Fig. 5 for a source temperature difference of $10^{\circ} \mathrm{C}$. When extending the results of 10 to $2^{\circ} \mathrm{C}$ (Fig. 9), it can be seen that the threshold remains almost the same, emphasising that below a ATR/STD 10 of 0.02 , the $v_{\mathrm{gw}} / v_{\mathrm{sw}}=$ ratio can no longer be determined.

\section{Discussion}

The results of this study demonstrate that temperature measurements with an accuracy of approximately $0.1^{\circ} \mathrm{C}$ can be obtained by fiber optic DTS. A more accurate temperature precision can be obtained with integration, either over longer time or greater 15 lengths of cable (Voigt et al., 2011). However, this would be at the expense of measuring finer spatial scales or more rapid temporal changes.

As mentioned earlier, Fig. 5 presents the ratio of apparent temperature response to source temperature difference (ATR/STD) vs. the velocity ratio of groundwater to surface water for all tests at $10^{\circ} \mathrm{C}$. From this figure it can be observed that at 20 ATR/STD below 0.02 , the $v_{\text {gw }} / v_{\text {sw }}$ ratios becomes uncertain and it is no longer possible to estimate the precise ratio of groundwater to surface water velocities. This result shows that for ATR/STD ratios below 0.02 , due to either a low groundwater velocity or high surface water velocity, groundwater discharge cannot be resolved in the field. Furthermore, it was seen from the dye tests that the surface water is mixing with the dis-

25 charging groundwater inside the injection section, especially when the groundwater velocity is very slow. When the groundwater velocity is very low, surface water enters the injection section and reduces the temperature difference significantly before reaching 
to the cable sitting above. As a result, the heat exchange occurs mostly within the injection section which consequently causes a lower apparent temperature response. The same situation is likely to be experienced in the field where surface water could penetrate, by hyporheic exchange, into shallow porous beds having low groundwater 5 outflow and thus change the temperature signal before reaching the surface and eventually a sensor cable situated on the surface (Cardenas and Wilson, 2007).

On the other hand, it is commonly assumed that complete mixing between the groundwater and the surface water has occurred when analysing DTS temperature data (Westhoff et al., 2007; Roth et al., 2010). However, the results of this study sug-

10 gests that the level of mixing strongly depends on the surface water and groundwater velocities as well as whether hot or cold groundwater is discharging (Fig. 8). For most flowing streams with adequate mixing this would not be an issue, but for slow flow, stagnant streams or sheltered lakes with little wind induced turbulence, it could well be an issue. In such cases it also becomes important whether the temperature difference 15 favours density stability (hot over cold water) or instability (cold over hot water).

When a fiber optic cable is in contact with the sediment surface, heat transfer via conduction to and from the sediment can play a role for the measured cable temperatures. The results of this study show that when the fiber optic cable is in contact with a flume glass bottom or with a gravel layer beneath the fiber optic cable, the temperature re20 sponse measured by the fiber optic cable is changed (Fig. 7). The results emphasise that probably both the higher level of convection due to the presence of gravel and the heat exchange due to conduction are influencing the measured temperature. This finding reinforces the heat transfer model proposed by Neilson et al. (2010) where the heat conduction is also a mechanism contributing to the heat transfer.

25 For field applications, the temperature difference between surface water and regional groundwater is often well constrained by measurements (Andersen and Acworth, 2009). The regional groundwater temperature can be constrained by measurements in deeper wells away from surface water bodies or estimated from the average annual air temperature. Further, if the surface water velocity is known from stream

$$
8177
$$

gauging and temperature measurements are obtained from a FO-DTS cable, then the velocity of groundwater discharge could be estimated from a semi-log relationship as presented in Fig. 9 and extracted as:

$$
v_{5}=v_{\mathrm{sw}} \cdot \operatorname{EXP}\left[14.5 \times\left(\frac{\mathrm{ATR}}{\mathrm{STD}}-0.37\right)\right]
$$

However, it should be noted that this correlation has been obtained in a well-controlled environment and its application to field settings may be influenced by additional uncertainty in the parameters due to heterogeneous field conditions. The equation is valid for ATR/STD ratios above 0.02 .

This threshold is partly defined by the FO-DTS system limits (i.e. noise levels and precision), but are also influenced by the physical conditions of the system, predominantly the velocity ratio and the temperature difference, but perhaps environmental conditions such as degree of mixing and the vertical velocity profile in the stream may play a larger role for field applications and raise the threshold for field conditions.

${ }_{15}$ In the study by Lauer et al. (2013), a $2 \%$ ratio of groundwater to surface water flow rates is identified as the limit in which the correct ratio can be extracted from temperature data for temperature differences from 1.2 to $4.2^{\circ} \mathrm{C}$. In contrast, the results of this study demonstrates that the limit of detection is at a ATR/STD of 0.02 which equals a $1 \%$ velocity ratio (or $0.4 \%$ flow ratio compared to $2 \%$ flow ratio identified by Lauer 20 and co-workers) for a $2^{\circ} \mathrm{C}$ temperature difference. In the work of Lauer et al. (2013) complete mixing of groundwater and surface water was assumed and used in the heatmass balance equation to estimate the groundwater discharge. Different assumptions may have contributed to the difference in the identified discharge detection limit in the two studies. 


\section{Summary}

In nutshell, experimental flume testing was carried out in this study to conduct a systematic assessment of temperature measurement of groundwater discharging into a stream using a FO-DTS system. The detection limit of DTS in groundwater discharge

5 to streams were investigated by varying several physical parameters and conditions: relative surface water (SW) and groundwater (GW) velocities $\left(v_{\mathrm{gw}} / v_{\mathrm{sw}}\right)$ between $0.21 \%$ and $61.7 \%$ (resulting in flow ratios of $0.07 \%$ to $21.5 \%$ ), temperature difference between SW-GW $\left(2-10^{\circ} \mathrm{C}\right)$, the direction of the temperature gradient (cold and hot water injections), and bed materials. From the results of this study, it is concluded that al-

10 though the limit of detection by DTS is a complex function of many parameters, the surface water velocity, and groundwater velocity and the temperature difference are the three main parameters determining the detection limits of groundwater discharge using DTS temperature measurement in a controlled environment.

It is also demonstrated that the FO-DTS system, as used in this flume experiment, 15 cannot reliably detect the velocity ratios of groundwater to surface water when the ratio of the apparent temperature response to the source temperature difference is below 0.02 .

\section{The Supplement related to this article is available online at doi:10.5194/hessd-11-8167-2014-supplement.}

20 Acknowledgements. Funding for this research was provided by the National Centre for Groundwater Research and Training, an Australian Government initiative, supported by the Australian Research Council and the National Water Commission. The authors would also like to acknowledge the financial support from Groundwater EIF fund through Connected Waters Initiative Research Centre. A big thanks goes to our colleagues lan Coghlan and Robert Jenkins at the

25 Water Research Laboratory for invaluable help with the flume setup and deployment of the ADV.

\section{References}

Andersen, M. and Acworth, R. I.: Stream-aquifer interactions in the Maules Creek catchment, Namoi Valley, New South Wales, Australia, Hydrogeol. J., 17, 2005-2021, doi:10.1007/s10040-009-0500-9, 2009.

5 Blakey, J. F.: Temperature of surface waters in the conterminous United States, in: USGS Hydrologic Atlas, United States Geological Survey, Washington, D.C., 235, 1966.

Briggs, M. A., Lautz, L. K., and McKenzie, J. M.: A comparison of fibre-optic distributed temperature sensing to traditional methods of evaluating groundwater inflow to streams, Hydrol. Process., 26, 1277-1290, doi:10.1002/hyp.8200, 2012.

- Cardenas, M. B. and Wilson, J. L.: Thermal regime of dune-covered sediments under gaining and losing water bodies, J. Geophys. Res., 112, G04013, doi:10.1029/2007jg000485, 2007.

Kersey, A. D.: Optical fiber sensors. Optical fiber sensors for permanent downwell monitoring applications in the oil and gas industry, IEICE Trans. Electron., E83-C, 400-404, 2000.

Lauer, F., Frede, H.-G., and Breuer, L.: Uncertainty assessment of quantifying spatially concen-

15 trated groundwater discharge to small streams by distributed temperature sensing, Water Resour. Res., 49, 400-407, doi:10.1002/wrcr.20060, 2013.

Neilson, B. T., Hatch, C. E., Ban, H., and Tyler, S. W.: Solar radiative heating of fiberoptic cables used to monitor temperatures in water, Water Resour. Res., 46, W08540, doi:10.1029/2009wr008354, 2010.

20 Rose, L., Krause, S., and Cassidy, N. J.: Capabilities and limitations of tracing spatial temperature patterns by fibre-optic distributed temperature sensing, Water Resour. Res., 49, 1741-1745, doi:10.1002/wrcr.20144, 2013.

Roth, T. R., Westhoff, M. C., Huwald, H., Huff, J. A., Rubin, J. F., Barrenetxea, G., Vetterli, M., Parriaux, A., Selker, J. S., and Parlange, M. B.: Stream temperature response to three riparian vegetation scenarios by use of a distributed temperature validated model, Environ. Sci. Technol., 44, 2072-2078, doi:10.1021/es902654f, 2010.

Selker, J., van de Giesen, N., Westhoff, M., Luxemburg, W., and Parlange, M. B.: Fiber optics opens window on stream dynamics, Geophys. Res. Lett., 33, L24401, doi:10.1029/2006gl027979, 2006a.

so Selker, J. S., Thévenaz, L., Huwald, H., Mallet, A., Luxemburg, W., van de Giesen, N., Stejskal, M., Zeman, J., Westhoff, M., and Parlange, M. B.: Distributed fiber- 
optic temperature sensing for hydrologic systems, Water Resour. Res., 42, W12202, doi:10.1029/2006wr005326, 2006b.

Suzuki, S.: Percolation measurements based on heat flow through soil with special reference to paddy fields, J. Geophys. Res., 65, 2883-2885, doi:10.1029/JZ065i009p02883, 1960.

5 Tyler, S. W., Selker, J. S., Hausner, M. B., Hatch, C. E., Torgersen, T., Thodal, C. E., and Schladow, S. G.: Environmental temperature sensing using Raman spectra DTS fiber-optic methods, Water Resour. Res., 45, W00D23, doi:10.1029/2008wr007052, 2009.

van de Giesen, N., Steele-Dunne, S. C., Jansen, J., Hoes, O., Hausner, M. B., Tyler, S., and Selker, J.: Double-ended calibration of fiber-optic Raman spectra distributed temperature sensing data, Sensors, 12, 5471-5485, 2012.

Voigt, D., Geel, J. L. W. A. v., and Kerkhof, O.: Spatio-temporal noise and drift in fiber optic distributed temperature sensing, Meas. Sci. Technol., 22, 085203, doi:10.1088/09570233/22/8/085203, 2011.

Westhoff, M. C., Savenije, H. H. G., Luxemburg, W. M. J ., Stelling, G. S., van de Giesen, N. C.,

15 Selker, J. S., Pfister, L., and Uhlenbrook, S.: A distributed stream temperature model using high resolution temperature observations, Hydrol. Earth Syst. Sci., 11, 1469-1480, doi:10.5194/hess-11-1469-2007, 2007.

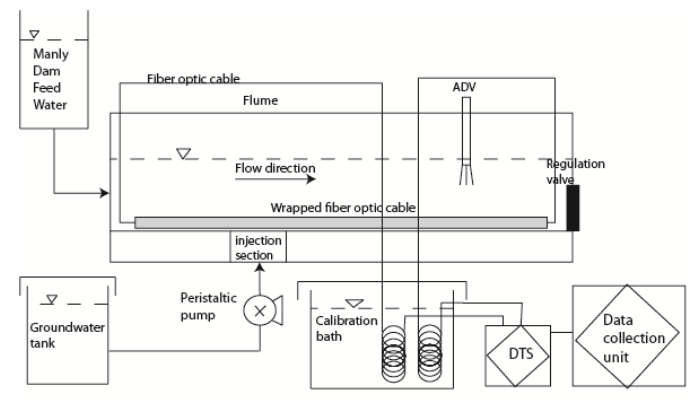

a)

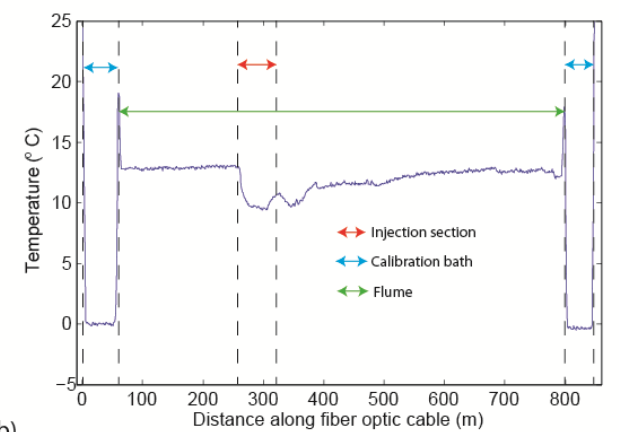

b)

Figure 1. (a) A schematic of the experimental setup, (b) example of the recorded temperatures along the cable showing lower temperatures at the injection section and calibration bath. 


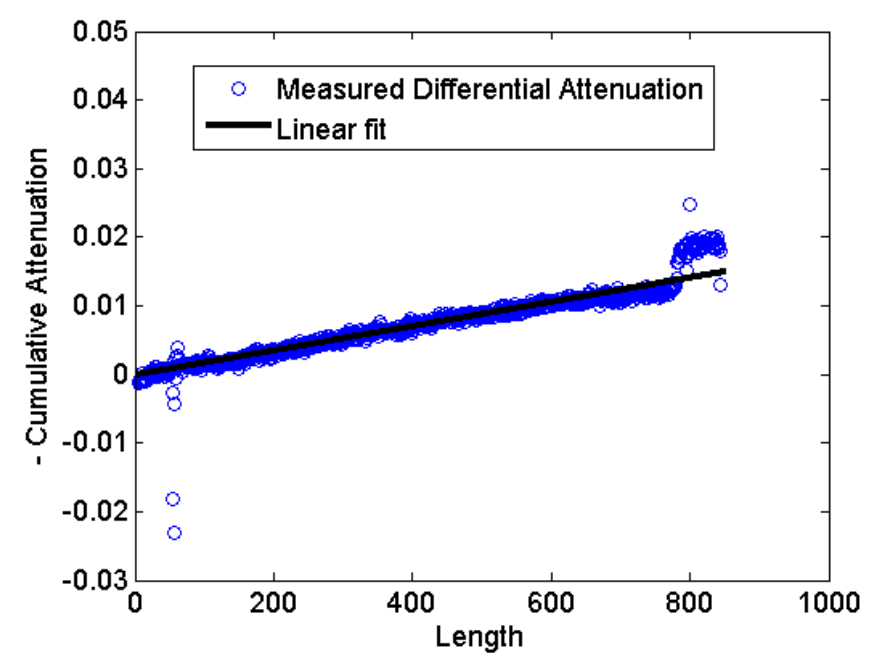

Figure 2. The cumulative differential attenuation along the cable with a linear fit to the readings showing sharp transitions in temperature. The stretches coincide with sharp transitions and splices along the cable.
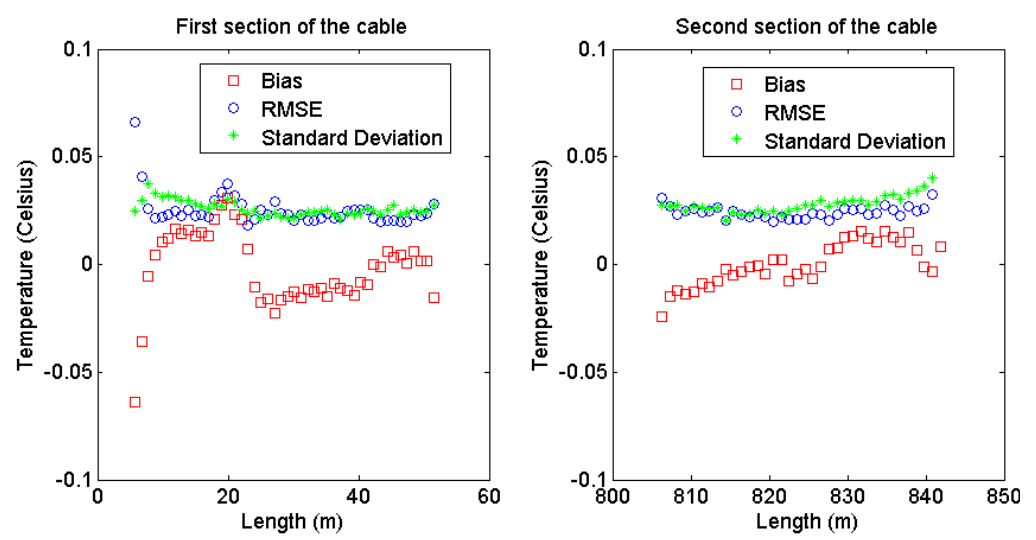

Figure 3. The RMSE, Bias and Standard deviation for all measurements along the two $50 \mathrm{~m}$ sections of the cable in the ice bath (compared with a Fluke reference thermometer). 


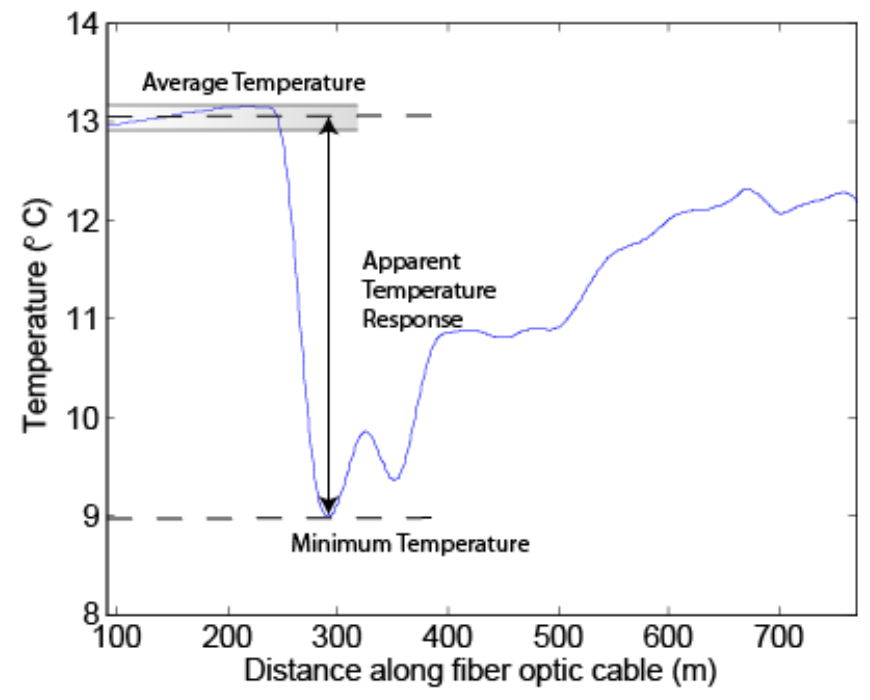

Figure 4. Example of calculating the apparent temperature response (ATR). The minimum temperature measured due to groundwater inflow is subtracted from the average background temperature upstream of the injection section.

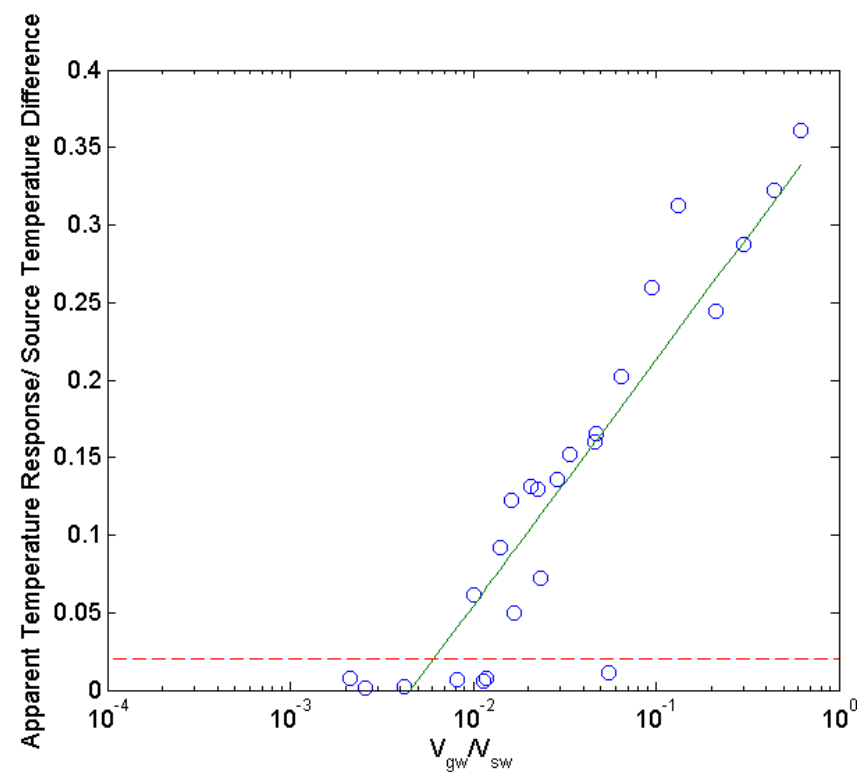

Figure 5. The ratio of apparent temperature response to the source temperature difference vs. the ratio of groundwater to surface water velocity. 

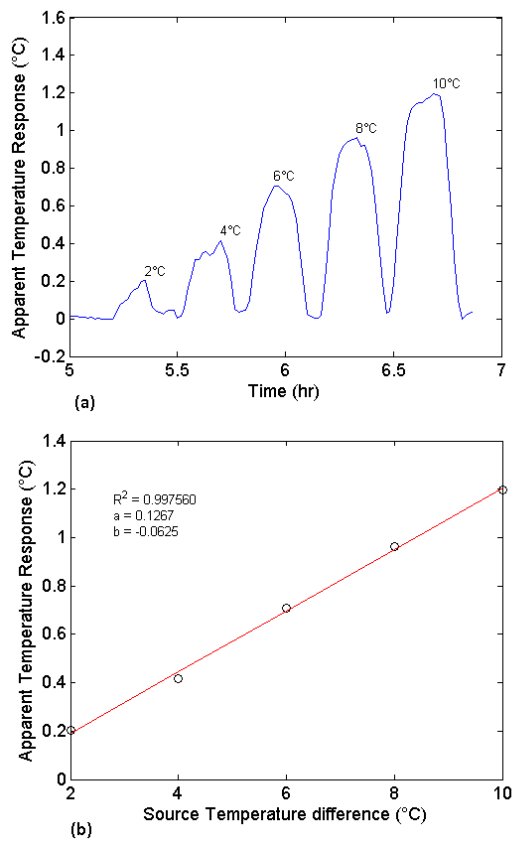

Figure 6. (a) Apparent temperature response of experiments with variable temperature difference between the background surface water and the groundwater for a surface water velocity of $0.11965 \mathrm{~m} \mathrm{~s}^{-1}$ and a groundwater velocity of $2.818 \times 10^{-3} \mathrm{~m} \mathrm{~s}^{-1}$; (b) apparent temperature response vs. the source temperature difference between the background surface water and the groundwater.

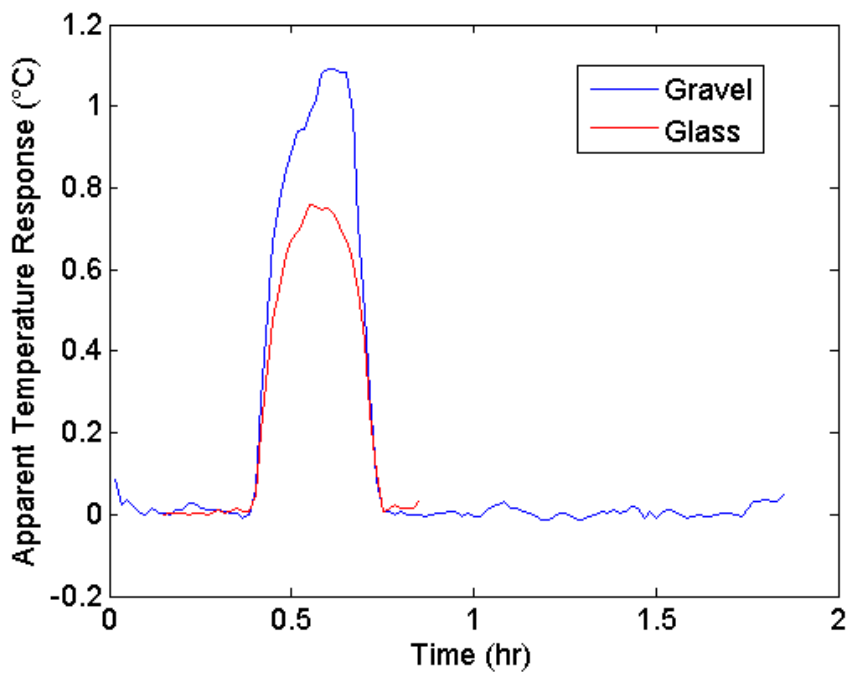

Figure 7. Apparent temperature response for tests with and without a gravel bed underneath the cable (surface water velocity: $0.11965 \mathrm{~m} \mathrm{~s}^{-1}$ and groundwater velocity: $2.818 \times 10^{-3} \mathrm{~m} \mathrm{~s}^{-1}$ ). 


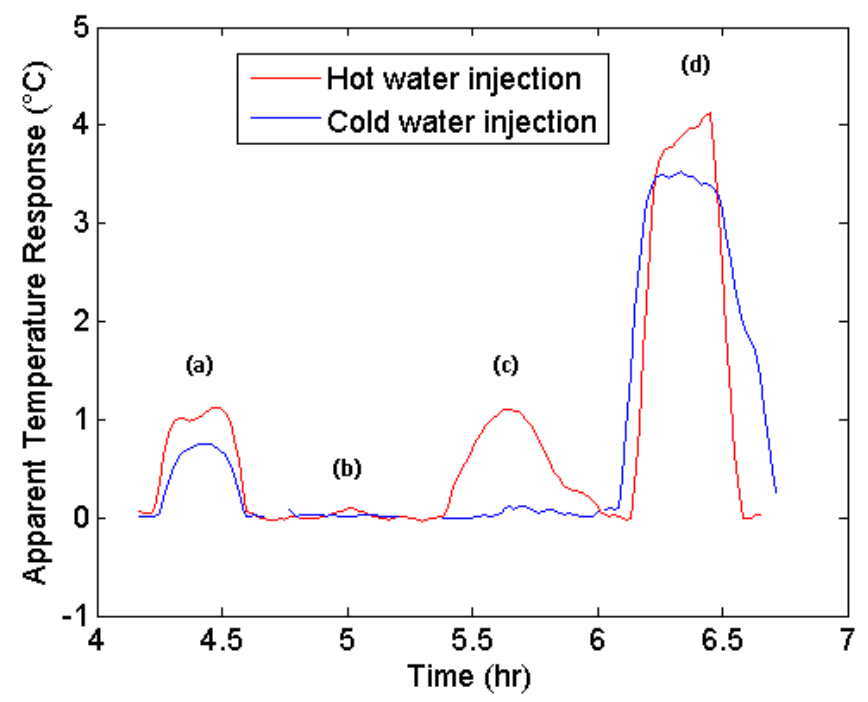

Figure 8. apparent temperature response for different injections of both hot and cold groundwater: (a) surface water velocity: $0.11965 \mathrm{~m} \mathrm{~s}^{-1}$ and groundwater velocity: $2.818 \times 10^{-3} \mathrm{~m} \mathrm{~s}^{-1}$; (b) surface water velocity: $0.11965 \mathrm{~m} \mathrm{~s}^{-1}$ and groundwater velocity: $2.52 \times 10^{-4} \mathrm{~m} \mathrm{~s}^{-1}$; (c) surface water velocity: $0.00457 \mathrm{~m} \mathrm{~s}^{-1}$ and groundwater velocity: $2.52 \times 10^{-4} \mathrm{~m} \mathrm{~s}^{-1}$; and (d) surface water velocity: $0.00457 \mathrm{~m} \mathrm{~s}^{-1}$ and groundwater velocity: $2.818 \times 10^{-3} \mathrm{~m} \mathrm{~s}^{-1}$.

8189

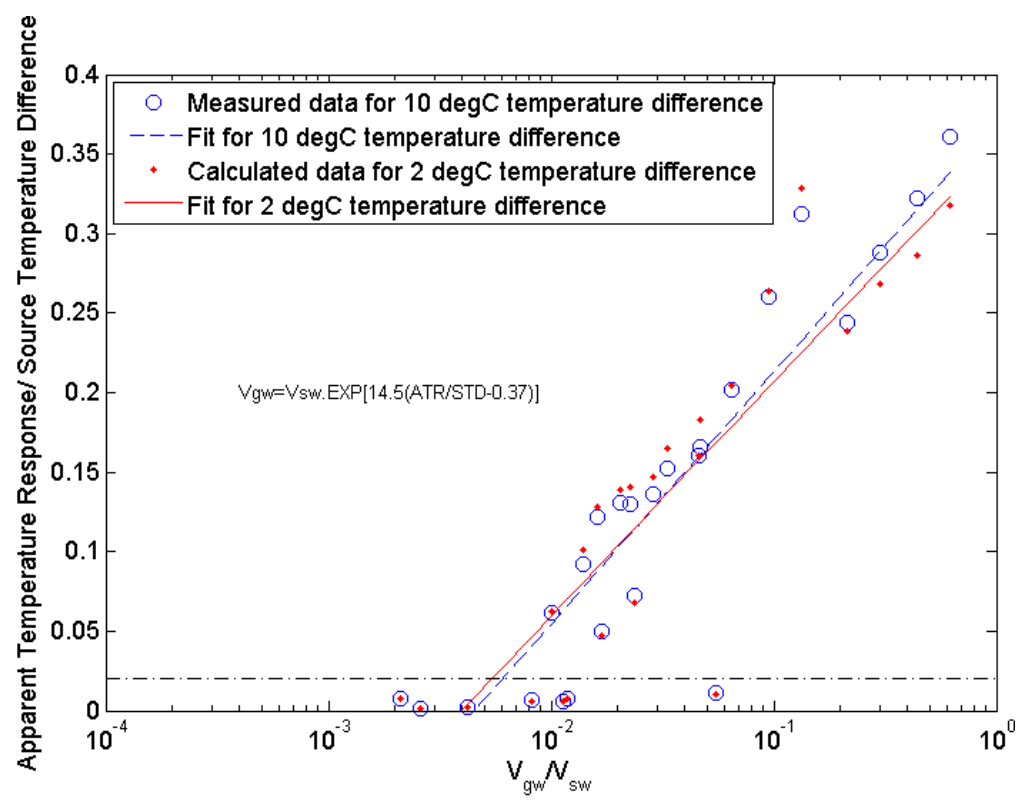

Figure 9. The ratio of apparent temperature response to the source temperature difference vs. the ratio of groundwater to surface water flow velocities at temperature differences of $10^{\circ} \mathrm{C}$ and $2{ }^{\circ} \mathrm{C}$ between the background surface water and the groundwater. The black horizontal line indicates the detection limit as represented by the ratio of apparent temperature response/source temperature difference of 0.02 . 